Article

\title{
Lending Interest Rate, Loaning Scale, and Government Subsidy Scale in Green Innovation
}

\author{
Shuanglian Chen ${ }^{1}$, Zhehao Huang ${ }^{1, *} \mathbb{C}$, Benjamin M. Drakeford ${ }^{2}\left(\mathbb{D}\right.$ and Pierre Failler ${ }^{2}(\mathbb{D}$ \\ 1 Guangzhou International Institute of Finance, Guangzhou University, Guangzhou 510405, China; \\ chensl@gzhu.edu.cn \\ 2 Department of Economics and Finance, Portsmouth Business School, University of Portsmouth, \\ Portsmouth PO1 3DE, UK; ben.drakeford@port.ac.uk (B.M.D.); pierre.failler@port.ac.uk (P.F.) \\ * Correspondence: zhehao.h@gzhu.edu.cn
}

Received: 21 October 2019; Accepted: 20 November 2019; Published: 21 November 2019

\begin{abstract}
Green loans are a way of financing green innovation. Two important factors, the lending interest rate and the loaning scale, should be focused on. In this paper, we explore the impact of lending interest rates and loaning scale on green innovation. We show that the incentive of green innovation strongly depends on the lending interest rate and the loaning scale through model analysis. Moreover, the dependence is summarized as a two-step strategy. In the first step, the lending interest rate should be lower than some rate thresholds given in the paper. Otherwise, green innovation fails to be stimulated. In the second step, if the lending interest rate is lower than the given rate threshold, then the practical loaning scale should lie between two thresholds of loaning scale derived in the paper, such that the green innovation will be stimulated. What is more, to guarantee the green effect of the innovation on the environment, we construct a threshold of loaning scale. If the loaning scale is larger than this threshold, then the innovation will show green effect on the environment. Otherwise, green innovation loses its environmental significance. The government stimulates green innovation through government subsidy. In this paper, we consider three kinds of government subsidy, including a subsidy for the bank, subsidy for the enterprise before and after implementing green innovation. Some appropriate government subsidy scales are presented.
\end{abstract}

Keywords: lending interest rate; loaning scale; government subsidy; green innovation; green finance

\section{Introduction}

For the purpose of environmental protection and sustainable development, green innovation has been gained worldwide attention. Zisopoulou et al. [1] pointed out that green economic growth is involved in the framework of WEF Nexus (Water, Energy, and Food Nexus) and Aghion et al. [2] claimed that no green growth is possible without innovation. Abernathy and Clark [3] developed a framework for analyzing the competitive implications of innovation. A diagrammatic topology of innovation is found in their work as Figure 1. Diamond Jr [4] introduced the Schumpeter 'creative destruction' nature of innovation by a review of evidence. A relatively pragmatic definition of green innovation given by Driessen and Hillebrand [5] explains that green innovation should produce significant environmental benefits. Another definition of green innovation, given by Chen et al. [6], consider it as hardware and software innovation relevant to green products. Technical innovation involving in energy saving, pollution prevention, waste recycling, design for green products, and environmental management are all essential parts of green innovation. As shown by Schiederig et al. [7], green innovation management is getting more and more important in both practice and academic research in the past several years. The shortage of resources allows us to consider more on the construction of green innovation and promotion of green innovation performance since they play key roles in sustainable development. 
For instance, Chang and Chen [8] explored the positive effect of green organizational identity on green innovation performance. Besides, they verified that both environmental commitment and environmental organizational legitimacy mediate between green organizational identity and green innovation performance. From the strategic management perspective, green innovation allows the industries, banks, and governments to coordinate development with each other. These facts drive us focusing on the study of green innovation. Works by Dutz and Sharma [9], Janicke [10], Lewis [11] show in the open economy, green innovation of a country or an industry is increasingly influenced by the external environment, especially the performance of banks and governments.

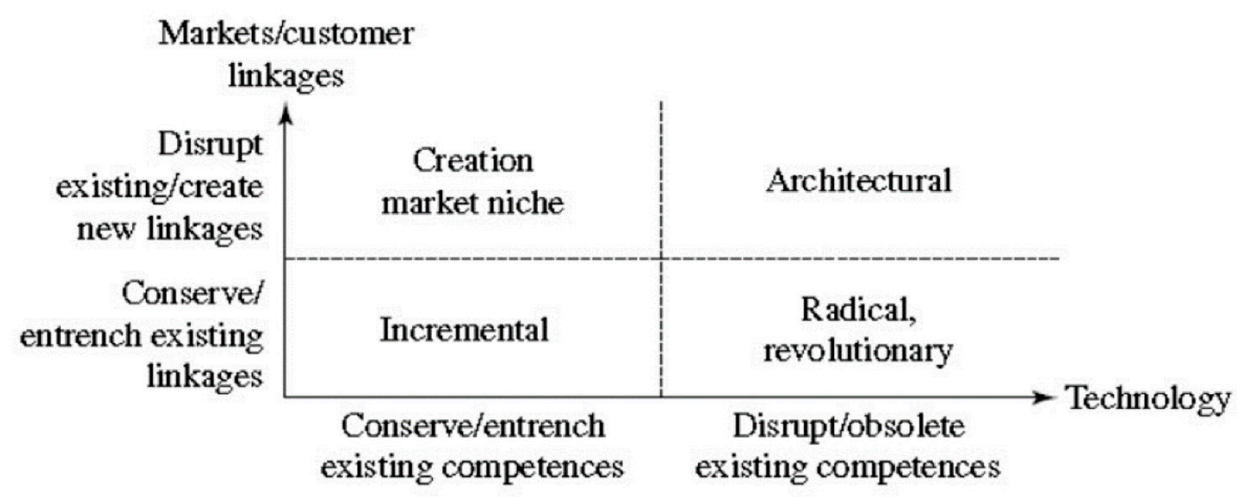

Figure 1. The diagrammatic topology of innovation implication in Abernathy and Clark [3].

Much literature concentrates on financial resource influence on innovation development. Aghion et al. [12] investigated whether financing choices differ systematically with R\&D intensity and found a nonlinear relationship between R\&D intensity and debt/asset ratio. Bartoloni [13] offered a twofold contribution to the empirical debate on the financing of innovation, the causality, and determinants. The results support the pecking order theory, as well as the existence of credit constraints, which seem to affect small innovative firms when compared with larger enterprises. Magri [14] shed light on special features in financial structure of small innovative firms and showed that small innovators rely less on financial debts and more on internal financial resources. Another finding is that small innovative firms show a lower investment sensitivity to cash flow. O'Brien [15] supported that financial slack should be a particularly critical strategic imperative for firms pursuing a competitive strategy premised on innovation. Schäfer et al. [16] investigated whether young, small and medium-sized enterprises classified as innovative firms, favor equity financing, and explored the factors determining their choices of financing mode. Del Río et al. [17] built a framework to incorporate the impact of firm internal factors such as resources, capabilities and competencies, and their interactions with external drivers on the development and adoption of eco-innovation. Marín-Vinuesa et al. [18] contributed empirically to the understanding of the impact that eco-innovation has on financial performance within the framework of the resource-based view. This literature focus on the relationship between capital structure and innovation performance. Some authors like Coad et al. [19] and D'Este et al. [20] investigated the barriers to innovation. The work of Coad et al. [19] contributes to the literature on barriers to innovation by accounting for heterogeneous effects that each barrier has on firms across the productivity distribution. D'Este et al. [20] argued that it is necessary to distinguish two kinds of barriers to innovation, revealed barriers and deterring barriers.

For green innovation, in this paper, the authors focus on the effect of the specific financing resource, the green loan, on the innovation performance. Some works, for example, by Benfratelloe et al. [21], Brown et al. [22], Kenney [23], Qamruzzaman and Wei [24] have shown that external financing, where banks play key roles, has a major impact on technical activities of enterprises. Small and medium-sized enterprises are usually with weak financial strength. Green loans provide them start-up funds of green innovation so that they are more competitive with peer companies. Benfratelloe et al. [21] verified that the process innovation can be affected by banking development, particularly for high-tech companies 
and those depending more on external finance. Concentrating on a provincial and industry-level innovation data set and regional lending structure in China's credit market from 1999 to 2007, Xin et al. [25] found that the level of innovation has been improved by bank loans. Works Hawkins and Kuang [26], Hsu et al. [27] showed that more external financing dependent or a more high-tech intensive industry tends to exhibit a disproportionately higher innovation level in countries with better-developed equity markets. The work of Amore et al. [28] shows that banking development plays an important role in technical progress and deregulation admits a significantly positive impact on quantity and quality of innovation activity. Kim and Park [29] pointed out that financial development leads to a reduction of $\mathrm{CO}_{2}$ emission by addressing the role of the financial market in deploying renewable energy. Later, Nanda and Nicholas [30], Zhuang [31] show the positive correlation between green loans and the innovation of enterprises.

Most existing literature on green loans concentrates on the influence of banking development and financial performance on green production and green innovation. Few pieces of literature care for quantitative analysis of green loans, particularly the role played by the loaning scale. Li et al. [32] started to explore problems relevant to loaning scales in their work. Enterprises are considered as principal objects in green innovation activities, where enterprises showed that the loaning scale is a crucial factor to stimulate green innovation by constructing series game models. By analyzing the profit of the enterprise through green innovation, they derived the loaning scale-dependent condition to stimulate green innovation. Besides, they obtained a threshold of the green loaning scale, which determines the green effect of the innovation project. Subsequently, following the work of Li et al. [32], Huang et al. [33] improved their results by considering the case that the success of green innovation also depends on the green loaning scale. They assumed that the larger capital input would enhance the success possibility of the green innovation project. Actually, this hypothesis is consistent with practice. In addition to similar results of $\mathrm{Li}$ et al. [32], they obtained a threshold of the green lending interest rate, which provides a reference when stimulating green innovation.

Energy consumption plays an important role in industrial production. The inefficient energy consumption is the main origin of environmental pollution, as some hazardous substances will be let out into the environment. Improving the energy efficiency by technology input, as a green technical innovation project, is an effective approach to reduce emission of hazardous substances. Thus, motivated by the works of Li et al. [32] and Huang et al. [33], in this paper, the authors devote to the further study on appropriate loaning scales and interest rates for green innovation projects to improve the energy efficiency. Comparing with the works of Li et al. [32] and Huang et al. [33], the promotion of the current paper is summarized as follows. Firstly, the authors introduce the initial fund demand for the innovation project. As long as the investment exceeds this fund demand, the green innovation will take effect. This part of capital is thought as the acquisition cost of basic equipment. Secondly, the improved energy efficiency through green innovation, depending on the green loaning scale, is set to be a hyperbolic type rather than an exponential type as that by Li et al. [32] and Huang et al. [33]. This modification will not lead to any robust problems in the model. With the hyperbolic typesetting for improved energy efficiency, the authors present explicit formulas for some specific loaning scales in green innovation. Explicit formulas for important quantities in engineering problems are usually preferred since it is convenient to apply and analyze the theoretical results. Thirdly, a uniform threshold of lending interest rate is shown independent of the loaning scale, which is different from that in Huang et al. [33] in which the threshold of lending interest rate depends on the loaning scale. In general, the loaning scale was found to be negatively related to interest spread [34]. Thus, the threshold of lending interest rate provides a meaningful reference for decision on the green loan and is more appropriate to be uniform with respect to the loaning scale. Fourthly, the incentive of green innovation depends on both the interest rate and the scale of the green loan. Moreover, dependence admits an order. The incentive first depends on the lending interest rate. If the lending interest rate is lower than the threshold, then the incentive depends on the loaning scale. The green innovation way considered in this paper also belongs to environmental innovation. Ghisetti and Rennings [35] separated the 
environmental innovation into two categories, those that reduce negative externalities and those targeting efficiency increases and cost savings. We claim that this paper targets both these categories.

Following the work of Huang et al. [33], to look at the stimulation of green innovation, the authors introduce the role of government into the game. The government subsidy is considered as an approach to stimulate green innovation projects. In reality, government subsidies are the result of bilateral Pigouvian taxation [36]. Governments have a social responsibility in environmental protection and sustainable development. Governments can encourage enterprises to transform from high-level consumption and high-pollution process flows to sustainable green innovative mode through regulatory and incentive measures. To accelerate the development of green innovation system and improve the quantity and quality of green innovation, enhancement of intensity and range of government subsidies are necessary. Paramati et al. [37] showed that governments and policymakers of emerging markets should provide favorable incentives to encourage green innovations. Berrone et al. [38] believed that regulation pressure shows a positive influence on green innovation of enterprises. Monasterolo and Raberto [39] showed the promotion of green growth by green public policies in a way of developing the EIRIN flow-of-funds behavioral model to simulate the introduction of green fiscal policies. Gerlach and Zheng [40] believed that the benefits of providing green production and effective incentives for the business are the two things to weigh in incentive management. Van Leeuwen and Mohnen [41] showed that environmental regulation has contribution to ecological investment and ecological innovation. As shown by Acemoglu et al. [42], Chen and Nie [43], Dzonzi-Undi and Li [44], subsidy provided by governments can promote the development of green innovation and alleviate environmental pressure directly for enterprises. Thus, enterprises are willing to conduct green innovation with reduced costs because of subsidies. Wang et al. [45] pointed out that the intention of enterprises to conduct innovation can be improved by a green insurance subsidy and government subsidy. Kemfert and Schmalz [46] illustrated that energy-intensive industries with poor production structure will be restrained by green loan policies. Tsai and Liao [47] showed that a high level of government subsidy will encourage enterprises to improve the ecological quality by applying environmental strategies. In the setting of this paper, the government provides subsidies for enterprises that apply for loan to perform green innovation. Huang et al. [33] claimed that government subsidy is indeed an effective approach to stimulate green innovation and green production, but they did not provide any information on the subsidy scale. The problem relevant to appropriate government subsidy scales is addressed in the current paper. Meanwhile, three kinds of government subsidy are considered, including a subsidy for the bank which issues green loans, subsidy for the enterprise before implementing green innovation, and subsidy for the enterprise after implementing green innovation. Thus, this section is also a further exploration of the results in the work of Huang et al. [33].

The methodology used in this paper is from game theory. Game theory has been widely used to discuss decisions between governments and enterprises in environmental protection. Huang et al. [48] investigated the influences of projects such as product design, supplier selection, transportation modes and pricing strategies on profit and greenhouse gas emission by game models. Tian et al. [49] analyzed the interest relation among the government, enterprises, and consumers by dynamic game theory, which interprets that subsidy is benefic to the diffusion of green supply chain management. Hafezalkotob et al. [50] considered the influences of environmental policies on green production and supply chains by multi-level game methods. They pointed that the government can reduce negative impacts of supply chains on the environment and encourage green production through tax and subsidy.

The rest of this paper is organized as follows. In Section 2, we propose some baseline models, including the environmental effect of the enterprise through green innovation, the energy efficiency of the enterprise depending on the green loaning scale, and the profit functions of the enterprise after green innovation with and without government subsidy. Enterprises are the most primary participants in green innovation activities. Green innovation should improve the environmental effect and increase the profits of enterprises. In Section 3, a threshold of the lending interest rate and three thresholds of the green loaning scales are derived. The threshold of the lending interest rate generates a precondition to 
stimulate green innovation. If the lending interest rate is lower than this threshold, then the incentive of green innovation depends on the loaning scale, which is subject to the thresholds. The green effect of the innovation project is also determined by the loaning scale. As long as the loaning scale is lower than some threshold, the innovation project will show its green effect. In Section 4, we focus on the government subsidy scales. Huang et al. [33] prove that government subsidy is an effective approach to stimulate green innovation. The following problem addressed in this paper is the determination of appropriate government subsidy scales. In Section 5 , we give a conclusion and some suggestions.

\section{Baseline Models}

We consider a representative enterprise in the market. We construct the models under free competition and assume that the industry is energy-intensive and depends heavily on energy consumption. We fix other inputs since we focus on the energy input and the environmental effect of energy usage in the production process. We denote the energy input $M$. The output of the enterprise in the production is given as

$$
Q=\kappa \theta M
$$

where $\theta$ is the energy efficiency, which depicts the percent conversion of unit energy, satisfying $0<\theta<1 . \kappa$ is the production efficiency, which depicts the output of a unit input, satisfying $\kappa>1$. In this way, according to Huang et al. [33], define a measure to capture the environmental effect made by the enterprise in the production as

$$
E=(1-\theta) M
$$

The measure (1) is interpreted as the inefficient usage of energy. The energy emission is proportional to the inefficient usage of the energy and leads to environmental problems, except for green inputs such as wind and solar power. For instance, the emission of $\mathrm{CO}_{2}$ from producing activities leads to global warming. Since $\partial E / \partial \theta=-M<0$ and $\partial E / \partial M=1-\theta>0$, low energy efficiency and high energy input lead to poor environmental effects. Although reducing the energy input and the production scale may be benefit to the environment, it does not contribute to the economic development. Technical innovation to improve energy efficiency is an effective approach. Banks provide financial support to companies to conduct technical innovations and they are encouraged to issue green loans for environmentally friendly projects. Denote $\theta_{L}$ the improved energy efficiency after the enterprise implements technical innovation with loaning scale $L$. The unit of the loaning scale can be thought as thousand dollars of hundred dollars. It depends on the practical applications of the model. The parameter $\theta_{0}$ represents the original energy efficiency before technical innovation. The improved energy efficiency depends heavily on the loaning scale. In this paper, the relation between energy efficiency and the loaning scale is supposed to satisfy the following formula

$$
\theta_{L}=\theta_{0} \text { as } L \leq L_{0}, \theta_{L}=\frac{\theta_{0}\left(1+\gamma\left(L-L_{0}\right)\right)}{1-\theta_{0}+\theta_{0}\left(1+\gamma\left(L-L_{0}\right)\right)} \text { as } L>L_{0}
$$

The parameter $\gamma$ represents the technical maturity. The energy efficiency can be improved with a low cost in the innovation process if the enterprise possesses a high technical maturity. The enterprise with a high technical maturity can achieve an expected level of energy efficiency by technical innovation with a relatively small loaning scale. The parameter $L_{0}$ is interpreted as the threshold effect of capital input in technical innovation. The energy efficiency cannot be improved through technical innovation until the capital input exceeds the threshold $L_{0}$. This capital input is considered as the acquisition cost of initial equipment. The setting of the improved energy efficiency (2) seems ad hoc. Actually, it is motivated by the logistic form, as seen in Dafermos et al. [51]. Since we focus on the effect of loaning scales in the green innovation project, the loaning scale should be a variable influencing the improvement of energy efficiency through technological innovation. In general, the improved energy efficiency depending on the loaning scale should be increasing with respect to the loaning scale. Meanwhile, with the investment increases, the improvement of energy efficiency will encounter a 
choke point, namely that if the energy efficiency has been at a high level, then even though a sufficiently large investment cannot lead to a remarkable improvement. We claim that the logistic form setting for improved energy efficiency can well capture these characteristics. One can see this from the marginal change of $\theta_{L}$ with respect to the loaning scale $L$

$$
\frac{\partial \theta_{L}}{\partial L}=\frac{\gamma \theta_{0}\left(1-\theta_{0}\right)}{\left(1-\theta_{0}+\theta_{0}\left(1+\gamma\left(L-L_{0}\right)\right)\right)^{2}}
$$

It is easy to see that $\partial \theta_{L} / \partial L>0$ and $\partial \theta_{L} / \partial L \rightarrow 0$ as $L \rightarrow \infty$, meaning the existence of chokepoint with a sufficiently large capital input in the innovation project. A similar setting for energy efficiency of an energy-intensive enterprise depending on investment can refer to Wang et al. [45]. We emphasize that the improved energy efficiency will play a key role in the decision on the green loaning scales. Figure 2 shows the shapes of the energy efficiency $\theta_{L}$ depending on the loaning scale $L$ with different values of the technical maturity $\gamma$. The threshold of initial capital input $L_{0}$ is set to be $L_{0}=100$ and the initial energy efficiency $\theta_{0}$ is set to be $\theta_{0}=0.2$. From the figure, we can see that for the same loaning scale, enterprise with high technical maturity can achieve a better result of technical innovation than an enterprise with low technical maturity. For instance, we suppose that the capital input for technical innovation is given as $L=200$. When the technical maturity $\gamma=0.05$, then $\theta_{200}=0.5998$. When $\gamma=0.5$, then $\theta_{200}=0.9272$.

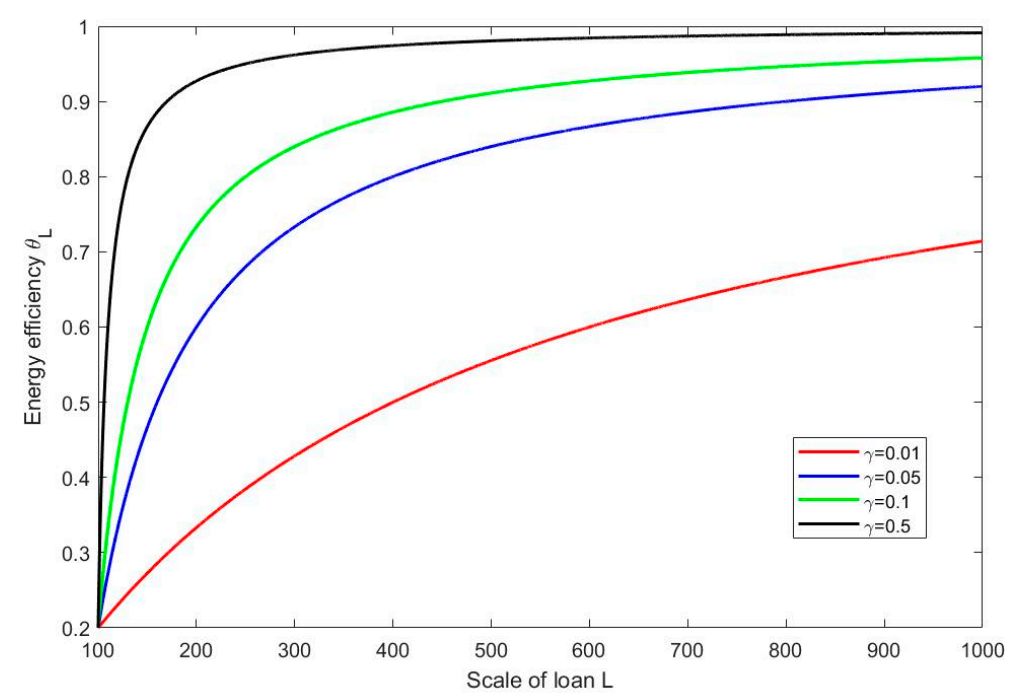

Figure 2. The tendencies of energy efficiency $\theta_{L}$ depending on the loaning scale $L$ with different values of technical maturity $\gamma$. The red line depicts the energy efficiency with the technical maturity $\gamma=0.01$. The blue line depicts the energy efficiency with the technical maturity $\gamma=0.05$. The green line depicts the energy efficiency with the technical maturity $\gamma=0.1$. The black line depicts the energy efficiency with the technical maturity $\gamma=0.5$.

Remark 1. The setting of the improved energy efficiency (2) is motivated by the logistic form, but where the exponential part $\exp \left(\gamma\left(L-L_{0}\right)\right)$ in the logistic form is substituted by a linear part $1+\gamma\left(L-L_{0}\right)$. The improved energy efficiency should be increasing and concave with respect to the loaning scale, which implies the choke point of technical promotion. The logistic form can satisfy these characteristics. Then a problem may arise, asking why we give up the use of the exponential part in the logistic form, because, with the linear part, some explicit formulas of the important quantities including the lending interest rate, green loaning scales, and government subsidy scales in the technical innovation process can be derived, which can be seen in the following sections. However, with the exponent part, we fail to solve the explicit formulas. In general, explicit solutions are usually preferred in some practical settings and engineering problems, since an explicit formula can show clear relations between objective variables and model parameters. Then it is conducive to understand the marginal changes of 
the objective variables with respect to the model parameters and put forward some effective control strategies for decision-makers. Meanwhile, we claim that the substitute of the exponent part by the linear part in the logistic form will not bring essential influence. It will not cause any additional trouble in the robust of the model. In addition, the parameter $\gamma$ in (2), meaning the technical maturity, is considered in the abstract. One can refer to Accenture [52] for a suitable definition tailored to innovation.

Technical innovation is an effective approach to reduce energy emission and improve environmental quality. The enterprise is encouraged to implement technical innovation with green loans. However, the enterprise pursues profit and focuses on whether technical innovation could bring higher profit. Thus, to stimulate the technical innovation project, we need to consider the profit function of the enterprise. Denote $\rho$ the unit price of the final product in the production. Then according to Huang et al. [33], the enterprise can earn a return as

$$
R=\rho Q=\rho \kappa \theta M
$$

Since we focus our attention on the energy input and fix other inputs, the cost function in the production is supposed to depend only on the energy input. Apparently, the cost is proportional to the input, namely that the larger input leads to a higher cost. Meanwhile, as the input increases, the marginal cost with respect to the input increases as well. Thus, the cost function should be increasing and convex with respect to the energy input. Accordingly, a quadratic polynomial is selected to capture the shape of the cost function, written as

$$
C=C_{0}+\alpha M+\beta M^{2}
$$

where $C_{0}$ is the fixed cost $\alpha M$ is the cost for energy input and $\beta M^{2}$ represents the cost incurred by production [45]. The enterprise needs to consider the profits before and after technical innovation and then make a decision on the innovation project. If the enterprise carries out conventional production, it will get a profit

$$
\pi=R-C=\rho \kappa \theta M-\alpha M-\beta M^{2}-C_{0}
$$

If the enterprise decides to implement the technical innovation by applying for a green loan from the bank, then the energy efficiency is improved from $\theta_{0}$ to $\theta_{L}$ with the capital support. Meanwhile, the enterprise pays the loaning interest to the bank. Thus, through technical innovation, the enterprise will get a profit

$$
\pi_{L}=\rho \kappa \theta_{L} M-\alpha M-\beta M^{2}-C_{0}-r L
$$

where $r$ is the green lending interest rate. The improvement of energy efficiency can stimulate energy input and bring a higher return to the enterprise. Meanwhile, more energy input, as well as the lending interest, leads to higher cost of the enterprise. This implies that technical innovation does not always bring a higher profit. The increase in profit depends heavily on the loaning scale. We believe that there should exist some loaning scales such that the profit with conventional production equals the profit with innovation, namely that $\pi=\pi_{L}$. These significant scales, which mean a zero profit through technical innovation, are thought of as boundaries separating two cases $\pi<\pi_{L}$ and $\pi>\pi_{L}$. The case $\pi>\pi_{L}$, meaning a less profit through technical innovation, may happen due to two reasons. One is the initial investment, namely that the acquisition cost. The increased return of the enterprise through technical innovation cannot cover the initial acquisition cost. The other is lending interest. The enterprise has to assume a large interest for a large loaning scale or a not enough low-interest rate. Thus, to stimulate the enterprise to implement technical innovation, the appropriate loaning scales, leading to an increased profit $\pi>\pi_{L}$, should be focused on.

For environmental protection and sustainable development, the government stimulates green innovation through effective approaches. The government subsidy for green innovation projects is considered in this paper. It has been proved by [33] that the government subsidy is an effective 
approach to stimulate green innovation, but there is no information on the subsidy scales. The problem on the government subsidy scales will be addressed in the following argument. With the objective to stimulate green innovation and green production, two kinds of government subsidy are involved in this paper, subsidy for the enterprise and subsidy for the bank. The enterprise needs financial support if it carries out technical innovation to improve energy efficiency. The bank provides capital for the green innovation project by issuing green loans with low-interest rates. To encourage the bank issuing green loan with a low-interest rate, the government provides subsidies for the bank. The enterprise expects a higher profit through technical innovation. However, as explained in the last paragraph, technical innovation cannot guarantee a higher profit. The enterprise might lose the confidence to implement innovation. Thus, to stimulate green innovation and improve environmental quality, the government subsidizes the enterprise if it decides to improve energy efficiency through technological innovation. Furthermore, the subsidy for the enterprise is divided into two parts, subsidies before and after technical innovation. Denote the subsidy scale for the bank by $S^{B}$. If the bank issues the green loan for the green innovation project, then the government provides the subsidy with the scale $S^{B}$ for the bank. On the other hand, denote the subsidy scales for the enterprise before the technical innovation and after the technical innovation by $S_{b}^{E}$ and $S_{a}^{E}$ respectively. Recall the profit function (4), the profit of the enterprise with government subsidy before implementing the technical innovation is written as

$$
\pi_{L, S_{b}^{E}}=\rho \kappa \theta_{L+S_{b}^{E}} M-\alpha M-\beta M^{2}-C_{0}-r L
$$

If the enterprise received the government subsidy before the technical innovation, the subsidy is involved in the investment of the innovation project, which leads to a further improvement of energy efficiency. The profit of the enterprise with government subsidy after implementing technical innovation is written as

$$
\pi_{L, S_{a}^{E}}=\rho \kappa \theta_{L} M-\alpha M-\beta M^{2}-C_{0}-r L+S_{a}^{E}
$$

The subsidy is added to the profit of the enterprise directly. Apparently, both these two ways of government subsidy will increase the profit of the enterprise. However, with the same subsidy scales, it is difficult to determine which way of subsidy will lead to a higher profit for the enterprise. It might depend on each model parameter, as well as the loaning scale and interest rate. If necessary, these two ways of government subsidy can be provided together to stimulate the green innovation project of the enterprise.

With the objective to stimulate green innovation and implement green production, basing on the models constructed above, in this paper, we consider three problems. Firstly, what loaning scale can lead to a higher profit of the enterprise. The enterprise improves energy efficiency through technical innovation, which results in a higher return. However, the enterprise should notice the lending interest results in a higher cost. The enterprise is willing to implement technical innovation as long as it can get a higher profit. From (4), we can see that the profit function of the enterprise depends heavily on the scale of the capital input. Secondly, what loaning scale can realize the green effect of the innovation. Although technical innovation can improve the energy efficiency of the enterprise, it will cause an increase in energy input and then an increase in energy emission. Thus, technical innovation may not show a green effect. We believe that there should be an appropriate loaning scale leading to green innovation. Thirdly, what government subsidy scale can stimulate green innovation. The government implements environmental protection and sustainable development through effective approaches. The government subsidy is an effective approach to stimulate green innovation. The subsequent problem concentrates on the subsidy scales. The government expects to provide subsidies with appropriate scales.

\section{Interest Rate and Green Loan Scale}

Green innovation needs financial support. The bank provides green loans for the enterprise to implement technical innovation. According to the baseline models constructed in Section 2, the technical 
innovation depends heavily on the loaning scale, as well as the lending interest rate. In this section, with the objective to stimulate the green innovation project, we explore problems on the green loaning scales and the lending interest rate. For instance, the enterprise would like to achieve an increase in profit through technical innovation. The bank issues green loans to support green innovation. The green effect of the innovation project lies on the loaning scale. Meanwhile, the lending interest rate is also an important factor in stimulating green innovation. In general, green loan admits a low-interest rate. Some threshold of the lending interest rate is derived in this section.

\subsection{Conventional Production Mode}

We first consider the conventional production mode of the enterprise, regarded as the benchmark in the decision on the technical innovation project, as well as the loaning scale. According to the profit function in conventional production mode (3), the enterprise maximizes the derivative of profit as the marginal profit with respect to the energy input equals to zero, namely that

$$
\frac{\partial \pi_{0}}{\partial M}=\rho \kappa \theta_{0}-\alpha-2 \beta M=0
$$

from which we can solve the optimal energy input as

$$
M_{0}^{*}=\frac{\rho \kappa \theta_{0}-\alpha}{2 \beta}
$$

Since $\alpha$ is the unit energy price, in practice, it should be much lower than the price of the final product $\rho$. In addition, the production efficiency satisfies $\kappa>1$. Hence, the optimal energy input is indeed larger than zero, which is consistent with the practice and acknowledged in the following argument. With this optimal scale of energy input, the maximum profit of the enterprise is given as

$$
\pi_{0}^{*}=\frac{\left(\rho \kappa \theta_{0}-\alpha\right)^{2}}{4 \beta}-C_{0}
$$

In conventional production, the effect made by the enterprise on the environment is given as

$$
E_{0}^{*}=\left(1-\theta_{0}\right) M_{0}^{*}=\frac{\left(1-\theta_{0}\right)\left(\rho \kappa \theta_{0}-\alpha\right)}{2 \beta}
$$

The profit is proportional to the square of the energy efficiency. Higher energy efficiency leads to a higher profit of the enterprise. The environmental effect through technical innovation is concave with respect to energy efficiency. It is easy to see that the enterprise makes the most negative effect on the environment when energy efficiency satisfies $\theta_{0}=1 / 2+\alpha / 2 \rho \kappa$.

\subsection{Green Innovation with Green Loan}

The enterprise pursues a higher profit. The motivation driving the enterprise to apply for a loan and implement technical innovation is the increase in profit after implementing the innovation. The profit function through technical innovation (4) depends heavily on the loaning scale, as well as the lending interest rate. In this section, we derive some specific loaning scales, which play important roles in stimulating green innovation.

This is a two-stage process. In the first stage, the enterprise applies for a loan from the bank with scale $L$. The loaning scale might be zero, which means the veto of the application. In the case of a zero loaning scale, the enterprise performs conventional production. In the second stage, the enterprise carries out green innovation and green production and then achieves the profit captured by (4). The process is addressed by a backward induction strategy. 
In the second stage, given the loaning scale, the enterprise selects the optimal energy input to maximize its profit. The optimal energy input satisfies the first-order condition

$$
\frac{\partial \pi_{L}}{\partial M}=\rho \kappa \theta_{L}-\alpha-2 \beta M=0
$$

which can be solved as

$$
M_{L}^{*}=\frac{\rho \kappa \theta_{L}-\alpha}{2 \beta}
$$

With this input scale, the maximum profit is given as

$$
\pi_{L}^{*}=\frac{\left(\rho \kappa \theta_{L}-\alpha\right)^{2}}{4 \beta}-C_{0}-r L
$$

In the first stage, the decision-makers of the enterprise make a decision to apply for a loan with an expected scale. The expected loaning scale should guarantee an increase in profit, namely that $\pi_{L}^{*}>\pi_{0}^{*}$. Comparing the difference between $\pi_{L}^{*}$ and $\pi_{0}^{*}$, one can get

$$
\pi_{L}^{*}-\pi_{0}^{*}=\frac{1}{4 \beta} \Phi(L)\left(1+\theta_{0} \gamma\left(L-L_{0}\right)\right)^{-2}, \Phi(L)=A L^{3}+B L^{2}+C L+D
$$

where $A, B, C$ and $D$ satisfy

$$
\begin{gathered}
A=-4 \beta \gamma^{2} \theta_{0}^{2} r \\
B=\gamma \theta_{0}\left(-8 r \beta+\gamma\left(1-\theta_{0}\right) \theta_{0} \kappa \rho\left(\left(1+\theta_{0}\right) \kappa \rho-2 \alpha\right)+8 r \beta \gamma \theta_{0} L_{0}\right) \\
=8 \beta \gamma \theta_{0}\left(\gamma \theta_{0} L_{0}-1\right) r+\gamma^{2}\left(1-\theta_{0}\right) \theta_{0}^{2} \kappa \rho\left(\left(1+\theta_{0}\right) \kappa \rho-2 \alpha\right) \\
C=2\left(-2 r \beta+\gamma\left(\theta_{0}-1\right) \theta_{0} \kappa \rho\left(\alpha-\theta_{0} \kappa \rho\right)\right) \\
+2 \gamma \theta_{0} L_{0}\left(4 r \beta+\gamma \theta_{0} \kappa \rho\left(2 \alpha\left(1-\theta_{0}\right)+\left(\theta_{0}^{2}-1\right) \kappa \rho\right)-2 r \beta \gamma \theta_{0} L_{0}\right) \\
=2 \gamma\left(\theta_{0}-1\right) \theta_{0} \kappa \rho\left(\alpha-\theta_{0} \kappa \rho+\gamma \theta_{0}\left(\left(1+\theta_{0}\right) \kappa \rho-2 \alpha\right) L_{0}\right)-4 \beta\left(\gamma \theta_{0} L_{0}-1\right)^{2} r
\end{gathered}
$$

and

$$
D=\gamma\left(1-\theta_{0}\right) \theta_{0} \kappa \rho L_{0}\left(2\left(\alpha-\theta_{0} \kappa \rho\right)+\gamma \theta_{0}\left(\left(1+\theta_{0}\right) \kappa \rho-2 \alpha\right) L_{0}\right)
$$

respectively. From (5), it is easy to see that

$$
\underset{L}{\operatorname{argmax}}\left(\pi_{L}^{*}-\pi_{0}^{*}\right)=\underset{L}{\operatorname{argmax}} \Phi(L)=\frac{-B+\sqrt{B^{2}-3 A C}}{3 A}
$$

and

$$
\max _{L}\left(\pi_{L}^{*}-\pi_{0}^{*}\right)=\frac{2 B^{2}-9 A B C+27 A^{2} D+\left(6 A C-2 B^{2}\right) \sqrt{B^{2}-3 A C}}{27 A^{2}}
$$

Letting $\max _{L}\left(\pi_{L}^{*}-\pi_{0}^{*}\right)=0$, one can get

$$
-B^{2} C^{2}+4 B^{3} D-18 A B C D+4 A C^{3}+27 A^{2} D^{2}=0
$$

Recalling the formulas of $A, B, C$ and $D,(6)$ is equivalent to

$$
f(r)=A_{0} r^{3}+B_{0} r^{2}+C_{0} r+D_{0}=0,
$$


where

$$
\begin{gathered}
A_{0}=-768 \beta^{3} \gamma^{3} \kappa^{2} \rho^{2}\left(\theta_{0}-1\right)^{2} \theta_{0}^{3}\left(\gamma L_{0} \theta_{0}-1\right)^{3} \\
B_{0}=-48 \beta^{2} \gamma^{4} \kappa^{2} \rho^{2}\left(\theta_{0}-1\right)^{2} \theta_{0}^{4}\left(4 \alpha-20 \alpha \kappa \rho+\kappa^{2} \rho^{2}+\theta_{0}\left(3 \kappa \rho\left(4 \alpha+6 \kappa \rho-5 \kappa \rho \theta_{0}\right)+H_{0}+J_{0}\right)\right) \\
C_{0}=-48 \beta \gamma^{5} \kappa^{3} \rho^{3}\left(\theta_{0}-1\right)^{3} \theta_{0}^{5}\left(-\alpha\left(4 \alpha^{2}-8 \alpha \kappa \rho+\kappa^{2} \rho^{2}\right)+M_{0}+N_{0}\right) \\
D_{0}=-12 \gamma^{6} \kappa^{4} \rho^{4}\left(\theta_{0}-1\right)^{4} \theta_{0}^{6}\left(\alpha-\kappa \rho \theta_{0}\right)^{2}\left(\kappa \rho+\kappa \rho \theta_{0}-2 \alpha\right)^{2} \\
H_{0}=4 \gamma^{2} L_{0}^{2} \theta_{0}\left(\alpha^{2}+4 \alpha \kappa \rho-2 \kappa^{2} \rho^{2}+3 \kappa \rho \theta_{0}\left(\kappa \rho \theta_{0}-2 \alpha\right)\right) \\
J_{0}=-4 \gamma L_{0}\left(2 \alpha^{2}-\alpha \kappa \rho+5 \kappa^{2} \rho^{2}+3 \kappa \rho \theta_{0}\left(2 \kappa \rho \theta_{0}-\alpha-3 \kappa \rho\right)\right) \\
M_{0}=\kappa \rho \theta_{0}\left(4 \alpha^{2}-14 \alpha \kappa \rho+\kappa^{2} \rho^{2}+3 \kappa \rho \theta_{0}\left(\alpha+2 \kappa \rho-\kappa \rho \theta_{0}\right)\right)
\end{gathered}
$$

and

$$
N_{0}=-\gamma L_{0} \theta_{0}\left(2 \alpha-\kappa \rho-\kappa \rho \theta_{0}\right)\left(2 \alpha^{2}+2 \alpha \kappa \rho-\kappa^{2} \rho^{2}+3 \kappa \rho \theta_{0}\left(\kappa \rho \theta_{0}-2 \alpha\right)\right)
$$

One can solve a threshold of the lending interest rate as

$$
r_{0}=\frac{-B_{0}-\sqrt[3]{\phi_{+}}-\sqrt[3]{\phi_{-}}}{3 A_{0}}
$$

where

$$
\begin{gathered}
\phi_{+}=\left(B_{0}^{2}-3 A_{0} C_{0}\right) B_{0}+3 A_{0} \frac{9 A_{0} D_{0}-B_{0} C_{0}+\sqrt{\Lambda}}{2} \\
\phi_{-}=\left(B_{0}^{2}-3 A_{0} C_{0}\right) B_{0}+3 A_{0} \frac{9 A_{0} D_{0}-B_{0} C_{0}-\sqrt{\Lambda}}{2} \\
\Lambda=\left(B_{0} C_{0}-9 A_{0} D_{0}\right)^{2}-4\left(B_{0}^{2}-3 A_{0} C_{0}\right)\left(C_{0}^{2}-3 B_{0} D_{0}\right)
\end{gathered}
$$

Figure 3 presents the tendency of the profit gap $\pi_{L}^{*}-\pi_{0}^{*}$ with respect to the loaning scale $L$, where the initial energy efficiency $\theta_{0}=0.2$, the production efficiency $\kappa=2$, the unit price of the final product $\rho=1$, the unit price of energy input $\alpha=0.1$, the cost coefficient $\beta=0.001$, the initial capital input $L_{0}=1000$, the technical maturity $\gamma=0.001$. Accordingly, the polynomial $\Phi(L)$ and $f(r)$ are calculated as

$$
\Phi(L)=-1.6 \times 10^{-10} r L^{3}+\left(-1.28 \times 10^{-6} r+1.408 \times 10^{-10}\right) L^{2}+\left(-8.96 \times 10^{-5}-0.00256 r\right) L-0.0512
$$

and

$$
f(r)=26843.5 r^{3}-419.43 r^{2}+117.105 r-7.30816=0
$$

from which we can solve the threshold of the interest rate as $r_{0}=0.0468$. If the lending interest rate satisfies $r_{0}=0.0468$, then the profit gap $\pi_{L}^{*}-\pi_{0}^{*}$ is tangent with the zero line at some loaning scale, where the profit gap touches the maximum. Thus, if the lending interest rate satisfies $r \geq 0.0468$, then for any loaning scale, it always holds that $\pi_{L}^{*} \leq \pi_{0}^{*}$, namely that technical innovation cannot bring higher profit for the enterprise than conventional production. If the lending interest rate satisfies $r<0.0468$, then from Figure 2, we can know that there exist two loaning scales, whose formulas are given as

$$
L_{+}=L_{1} \vee L_{2}, L_{-}=L_{1} \wedge L_{2}
$$

where

$$
\begin{gathered}
L_{1}=\frac{-B+\sqrt{B^{2}-3 A C}(\cos \Theta+\sqrt{3} \sin \Theta)}{3 A} \\
L_{2}=\frac{-B+\sqrt{B^{2}-3 A C}(\cos \Theta-\sqrt{3} \sin \Theta)}{3 A} \\
\Theta=\frac{1}{3} \arccos \frac{2\left(B^{2}-3 A C\right) B-3 A(B C-9 A D)}{3\left(B^{2}-3 A C\right) \sqrt{B^{2}-3 A C}}
\end{gathered}
$$




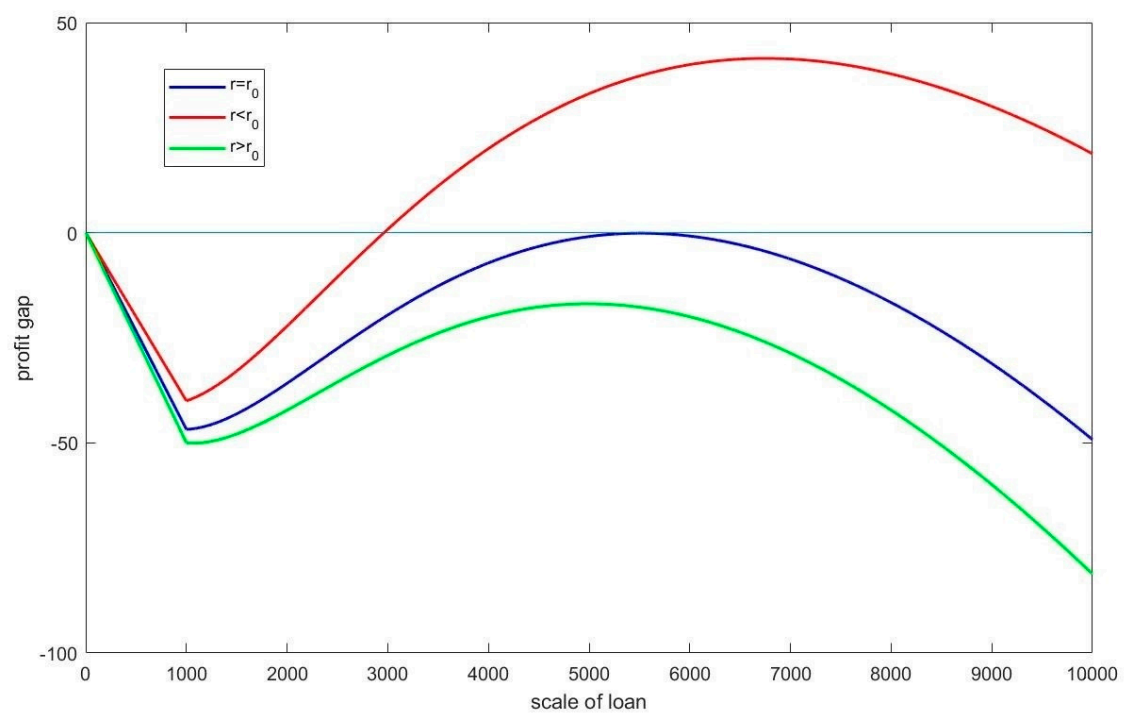

Figure 3. The profit gap $\pi_{L}^{*}-\pi_{0}^{*}$ with respect to the loaning scale. The red line depicts the case where the lending interest rate $r$ is smaller than the threshold $r_{0}$. The blue line depicts the case where the lending interest rate $r$ equals to the threshold $r_{0}$. The green line depicts the case where the lending interest rate $r$ is larger than the threshold $r_{0}$.

If the loaning scale $L$ satisfies $L_{-}<L<L_{+}$, then it holds that $\pi_{L}^{*}>\pi_{0^{\prime}}^{*}$ which means that the enterprise can achieve an increase in profit through technical innovation. Otherwise, it holds that $\pi_{L}^{*} \leq \pi_{0}^{*}$. The technical innovation cannot increase the profit of the enterprise. We set the values of the model parameters as above, namely that $\theta_{0}=0.2, \kappa=2, \rho=1, \alpha=0.1, \beta=0.001, L_{0}=1000$, $\gamma=0.001$. Then, we set the lending interest rate $r=0.04<0.0468$. Accordingly, $L_{+}, L_{-}$are calculated as $L_{+}=11,277, L_{-}=2963$, namely that if the lending interest rate is 0.04 , then the loaning scale between 2963 and 11,277 can stimulate the enterprise to implement technical innovation. By summarizing the above quantitative analysis, we have the following proposition.

Proposition 1. If the lending interest rate is smaller than the threshold given in (8), then there exist two specific loaning scales given in (9). If the loaning scale received by the enterprise from the bank is between these two loaning scales given in (9), then the enterprise can achieve an increase in the profit through technical innovation. Thus, the green innovation project can be stimulated. Otherwise, if the loaning scale received by the enterprise is outside of the range between the two loaning scales given in (9), the enterprise fails to achieve an increase of the profit through technical innovation. If the lending interest rate is larger than the threshold given in (8), then the enterprise fails to achieve an increase of the profit through technical innovation with any loaning scale.

Firstly, the incentive for green innovation depends on the lending interest rate. In general, the current funding level of the enterprise cannot well support the technical innovation project. Hence, the enterprise has to apply for a loan from the bank. Since pursuing profit is always the objective of the enterprise, a high lending interest rate might increase the cost of innovation such that the enterprise fails to achieve an increase in profit. Thus, the high lending interest rate goes against the incentive of green innovation. An appropriate lending interest rate should be focused on. Proposition 1 provides a threshold of the lending interest rate as a benchmark. The lending interest rate for the enterprise should be lower than the given threshold such that the green innovation will be stimulated. If the lending interest rate is higher than the threshold, the enterprise has to pay an overlarge cost of innovation such that it is impossible to get a higher profit than the conventional production.

Secondly, supposing that the lending interest rate for the enterprise is lower than the threshold in Proposition 1, the incentive of green innovation also depends on the loaning scale. Proposition 1indicates that even though the lending interest rate is lower than the given threshold, the enterprise 
still cannot guarantee a higher profit through green innovation. Furthermore, it is determined by the loaning scale. From Proposition 1, if the loaning scale received by the enterprise is between the two given specific scales, the enterprise can return a higher profit than conventional production through green innovation. Otherwise, it fails to increase profit. Therefore, an appropriate loaning scale should be focused on as well when stimulating green innovation. Both the appropriate lending interest rate and appropriate loaning scale will succeed to stimulate the green innovation.

\subsection{Green Loan Improving Environmental Effect}

The objective of the green loan is to improve the environmental effect of some production and innovation activities. It should play an important role in supporting green projects. In this paper, the bank provides capital for the enterprise to carry out the green innovation project and improve energy efficiency by issuing green loans. The improvement of energy efficiency will reduce energy emission and improve environmental quality. Meanwhile, the improvement of energy efficiency will lead to larger energy input. As a result of larger energy emission, it is adverse to the environment. According to the measure of environmental effect (1), the loaning scale plays a key role in controlling the energy emission. Hence, an appropriate loaning scale in stimulating green innovation not only increases the profit of the enterprise but also improves the environmental quality. In this section, we focus on the green loaning scale. The environmental effect made by the enterprise which implements green innovation with a loaning scale $L$ is measured by

$$
E_{L}^{*}=\left(1-\theta_{L}\right) M_{L}^{*}=\frac{\left(1-\theta_{0}\right)\left(\rho \kappa \theta_{0}-\alpha\right)}{2 \beta}
$$

for $L \leq L_{0}$ and

$$
E_{L}^{*}=\left(1-\theta_{L}\right) M_{L}^{*}=\frac{\left(1-\theta_{0}\right)\left(\rho \kappa \theta_{0}-\rho \kappa \theta_{0} \gamma L_{0}-\alpha+\alpha \gamma \theta_{0} L_{0}+\left(\rho \kappa \theta_{0} \gamma-\alpha \theta_{0} \gamma\right) L\right)}{2 \beta\left(1+\gamma \theta_{0}\left(L-L_{0}\right)\right)^{2}}
$$

for $L>L_{0}$. With the objective to improve the environmental effect of the enterprise, an appropriate green loaning scale should guarantee the relation $E_{L}^{*}<E_{0}^{*}$. Comparing the difference between $E_{L}^{*}$ and $E_{0}^{*}$ gives

$$
E_{L}^{*}-E_{0}^{*}=\frac{1-\theta_{0}}{2 \beta} \Psi(L)\left(1+\gamma \theta_{0}\left(L-L_{0}\right)\right)^{-2}, \Psi(L)=a L^{2}+b L+c, L>L_{0}
$$

where

$$
\begin{gathered}
a=\gamma^{2} \theta_{0}^{2}\left(\alpha-\kappa \rho \theta_{0}\right) \\
b=\gamma \theta_{0}\left(\alpha+\kappa \rho-2 \kappa \rho \theta_{0}+2 \gamma \theta_{0}\left(\theta_{0} \kappa \rho-\alpha\right) L_{0}\right) \\
c=-\gamma \theta_{0} L_{0}\left(\alpha+\left(1-2 \theta_{0}\right) \kappa \rho+\gamma \theta_{0}\left(\rho \kappa \theta_{0}-\alpha\right) L_{0}\right)
\end{gathered}
$$

If the original energy efficiency satisfies $\theta_{0}<1 / 2+\alpha / 2 \rho \kappa$, then we can solve a loaning scale by letting $E_{L}^{*}-E_{0}^{*}=0$, whose formula is given as

$$
L^{*}=\frac{\alpha+\kappa \rho-2 \kappa \rho \theta_{0}+2 \gamma \theta_{0}\left(\rho \kappa \theta_{0}-\alpha\right) L_{0}+\left|\alpha+\left(1-2 \theta_{0}\right) \kappa \rho\right|}{2 \gamma \theta_{0}\left(\kappa \rho \theta_{0}-\alpha\right)}
$$

In this case, if the loaning scale satisfies $L>L^{*}$, then the environmental effect satisfies $E_{L}^{*}<E_{0}^{*}$. If the loaning scale satisfies $L_{0}<L<L^{*}$, then the environmental effect satisfies $E_{L}^{*}>E_{0}^{*}$. On the other hand, if the original energy efficiency satisfies $\theta_{0} \geq 1 / 2+\alpha / 2 \rho \kappa$, then it is easy to understand that any loaning scale larger than the initial capital input $L_{0}$ can guarantee the relation $E_{L}^{*}<E_{0}^{*}$. Figures 4 and 5 show the tendency of the environmental effect $E_{L}^{*}$ depending on the loaning scale $L$. The model parameters are set to be $\alpha=0.1, \beta=0.001, \gamma=0.001, \kappa=2, \rho=1, L_{0}=1000$. Thus, $1 / 2+\alpha / 2 \rho \kappa=0.525$. In Figure 4 , the original energy efficiency is set to be $\theta_{0}=0.3<0.525$. Then the threshold of loaning scale $L^{*}$ exists, satisfying $L^{*}=7000$. We can see that for $L>7000$, it holds 
that $E_{L}^{*}<E_{0}^{*}$, the red part of the line in Figure 3. In Figure 5, the original energy efficiency is set to be $\theta_{0}=0.7>0.525$. Thus, any loaning scale larger than $L_{0}$ will lead to $E_{L}^{*}<E_{0}^{*}$. Summarizing the above quantitative analysis, we have the following proposition.

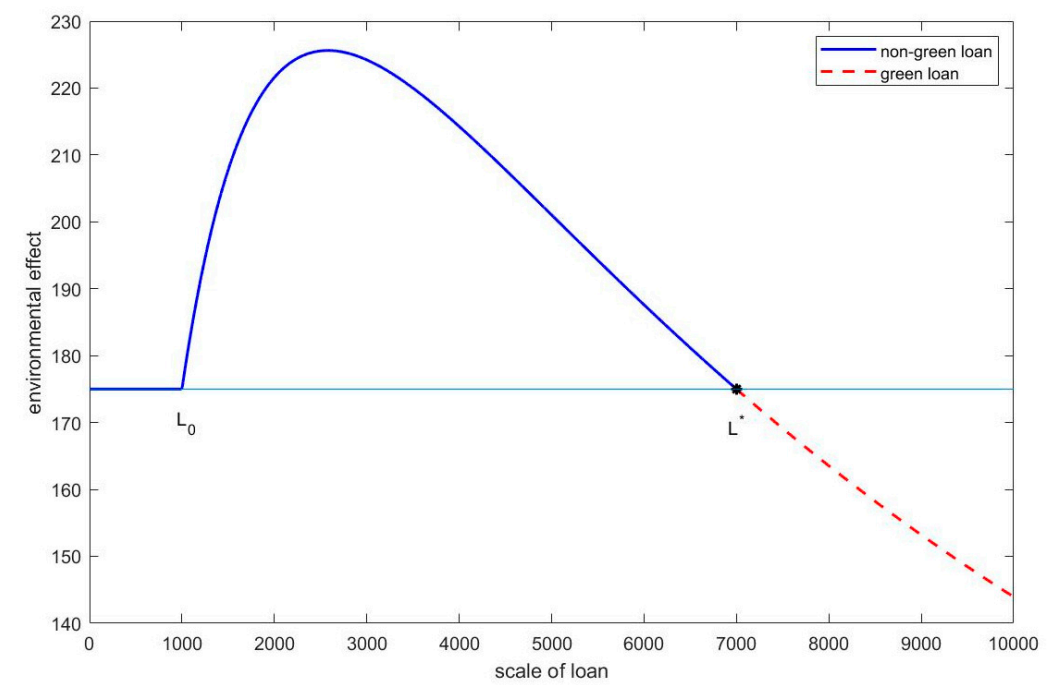

Figure 4. The tendency of the environmental effect $E_{L}^{*}$ with respect to the loaning scale. The original energy efficiency is set to be $\theta_{0}=0.3$. The red part means that the environmental effect satisfies $E_{L}^{*}<E_{0}^{*}$. The blue part means that the environmental effect satisfies $E_{L}^{*} \geq E_{0}^{*}$.

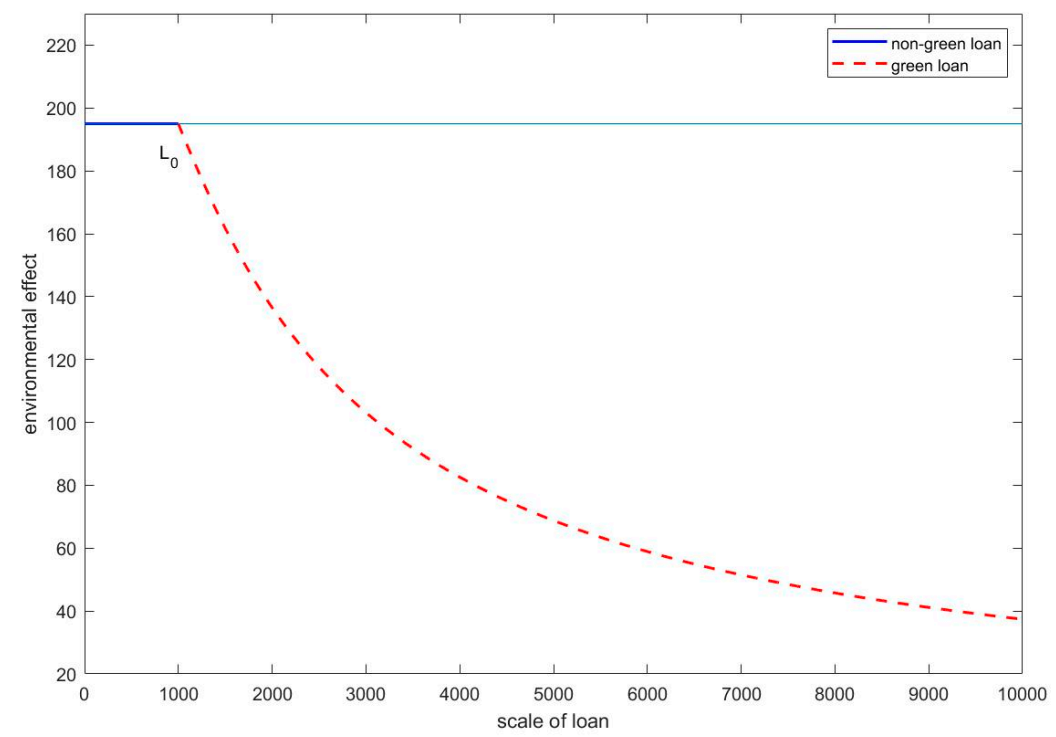

Figure 5. The tendency of the environmental effect $E_{L}^{*}$ with respect to the loaning scale. The original energy efficiency is set to be $\theta_{0}=0.7$. The red part means that the environmental effect satisfies $E_{L}^{*}<E_{0}^{*}$. The blue part means that the environmental effect satisfies $E_{L}^{*} \geq E_{0}^{*}$.

Proposition 2. If the original energy efficiency is lower than the specific value $1 / 2+\alpha / 2 \rho \kappa$, then there exists a threshold of the loaning scale given in (10). If the loaning scale received by the enterprise is larger than this threshold, then the energy emission can be reduced through the green innovation and the environmental effect made by the enterprise is improved. If the loaning scale is smaller than the threshold, then more energy emission comes into being due to the technical innovation and the environmental effect made by the enterprise becomes worse than conventional production. If the original energy efficiency is higher than the specific value $1 / 2+\alpha / 2 \rho \kappa$, then besides the initial acquisition cost of equipment, with any loaning scale for the green innovation, the environmental effect made by the enterprise can be improved. 
The enterprise with a lower original energy efficiency needs a larger loaning scale to improve the environmental effect through green innovation. On the contrary, if the enterprise admits a high original energy efficiency, then a small loaning scale can improve the environmental effect. Firstly, Proposition 2 indicates that if the original energy efficiency of the enterprise is larger than some specific value, then any loaning scale larger than the initial capital input can improve the environmental effect of the enterprise. Otherwise, some appropriate loaning scale should be needed to show the green effect. Secondly, Proposition 2 presents a threshold of the green loaning scale, following the case where the original energy efficiency of the enterprise is smaller than the given specific value. If the loaning scale received by the enterprise is larger than the threshold given in Proposition 2, then the technical innovation project can show the green effect on the environment. Otherwise, the technical innovation fails to be a green project.

Associating the results in Proposition 1 with Proposition 2, some suggestions on the green loaning scale stimulating the enterprise to implement green innovation are summarized as follows.

Firstly, if the original energy efficiency of the enterprise is smaller than the specific value $1 / 2+\alpha / 2 \rho \kappa$, and in addition, the threshold scale $L^{*}$ given in (10) lies between the scales $L_{+}$and $L_{-}$ given in (9), then a loaning scale larger than the threshold $L^{*}$ but smaller than the upper scale $L_{+}$is appropriate. Thus, the scale between scale $L_{+}$and $L_{-}$not only increases the profit of the enterprise but also improves the environmental quality.

Secondly, if the original energy efficiency of the enterprise is higher than the specific value $1 / 2+\alpha / 2 \rho \kappa$, then any loaning scale between the scales $L_{+}$and $L_{-}$given in (9) is appropriate. Moreover, from the viewpoint of green production, a loaning scale between $L_{+}$and $L_{-}$but close to $L_{+}$ is more preferred, since it will result in better environmental effect.

Thirdly, if the original energy efficiency of the enterprise is lower than the specific value $1 / 2+\alpha / 2 \rho \kappa$ and the threshold scale given in (10) is lower than the scale $L_{-}$given in (9), then a scale of loan close to the scale $L_{+}$is more preferred as well.

Fourthly, if the original energy efficiency of the enterprise is lower than the specific value and the threshold scale given in (10) is higher than the scale $L_{+}$given in (9), then there does not exist an appropriate loaning scale to improve the environmental effect of the enterprise. In this case, the government subsidy should play an important role, which will be discussed in the following section.

\section{Government Subsidy Scale}

The government works on environmental protection and sustainable development through effective approaches. In this paper, following the work of Huang et al. [33], the government subsidy is still considered as an approach to stimulate green innovation. They showed that the government subsidy is effective to stimulate green innovation and improve environmental quality. However, the government subsidy scale is unclear. In this section, we focus on the government subsidy scale. The enterprise and the bank are two primary participants in the green innovation activity. The corporation between the enterprise and the bank guarantees the implementation of the green innovation project. Thus, if necessary, the government should provide subsidies for both the enterprise and the bank.

\subsection{Government Subsidy for the Bank}

The bank provides capital for the green innovation project. Usually, green loans require low lending interest rates relative to general commercial loans, which may weaken the willingness of the bank to issue green loans. Proposition 1 shows that if the lending interest rate is higher than the threshold given in (8), the green innovation cannot be stimulated since the enterprise fails to return a larger profit through green innovation than conventional production. Thus, to stimulate green innovation, a relatively low lending interest rate is preferred. The government encourages the bank to issue green loans with low lending interest rates by providing subsidies. An example of interest rate subsidy is provided by the Bank of China's suggestion of strengthening interest rate discounts in green loans [53]. Also, the government may lower the interest rates by the direct open market operation 
of offering partial or total guarantees for the loan. Green loans have a 15 years average maturity, the market increased by 30\% from 2017 to 2018. According to the 2019 NGFS report [54], financial risk of green loan default is at $5.7 \%$ while non-green loans are at $8.5 \%$, which will encourage a positive trend regarding risk-averse lenders.

Denote the practical lending interest rate for the enterprise by $r$. The loaning scale received by the enterprise from the bank is denoted by $L$. According to Proposition 1, the premise that green innovation can be successfully stimulated is that the lending interest rate $r$ satisfies $r<\hat{r}$, where $\hat{r}$ is the threshold given in (8). Otherwise, innovation fails to be stimulated. Thus, to encourage the issue of green loan, if the bank approves the lending interest rate lower than the threshold in (8), the government subsidizes the bank with a scale

$$
S^{B}=(\hat{r}-r) L
$$

We summarize the discussion as the following proposition.

Proposition 3. If the bank approves the green loan for the enterprise with the interest rate lower than the threshold given in (8), then the bank will receive a subsidy from the government. The subsidy scale is the difference between the lending interest with the threshold interest rate in (8) and the practical interest from the enterprise, i.e., (11). The government compensates for the possible potential loss of the bank due to the issue of green loans with a low-interest rate such that green innovation can be stimulated.

\subsection{Government Subsidy for the Enterprise}

Proposition 1 indicates that the incentive of green innovation depends both on the interest rate and the green loaning scale. This results from the objective of the enterprise, pursuing a higher profit. The government encourages the bank to issue green loans with low-interest rates by providing subsidies such that the lending interest rate could be lower than the threshold given in (8). The subsidy scale for the bank has been discussed in the last subsection. In this subsection, we pay our attention to the subsidy for the enterprise. We have the precondition that the government has subsidies for the bank and the lending interest rate for the enterprise is lower than the threshold given in (8). Thus, the incentive for green innovation relies on the loaning scale.

With the objective of environmental protection and sustainable development, the government would like to stimulate the enterprise to implement green innovation improving energy efficiency. According to Proposition 2, the environmental effect of the innovation activity also depends on the loaning scale. If the relation $\theta_{0} \geq 1 / 2+\alpha / 2 \rho \kappa$ holds, then any loaning scale larger than the initial capital input $L_{0}$ can lead to a positive environmental effect, i.e., $E_{L}^{*}<E_{0}^{*}$. For this case, if the practical loaning scale $L$ received by the enterprise is smaller than the threshold scale $L_{-}$given in (9), then the government subsidies the enterprise before implementing the technical innovation with a scale $S_{b}^{E}$ larger than the threshold

$$
S_{b}^{E *}=L_{-}-L
$$

If the loaning scale $L$ received by the enterprise is between the scales $L_{-}$and $L_{+}$in (9), then the government does not need to provide a subsidy for the enterprise. If the loaning scale $L$ is larger than the scale $L_{+}$in (9), then the government subsidizes the enterprise after the technical innovation with a scale $S_{b}^{E}$ larger than the threshold

$$
S_{a}^{E *}=\pi_{L_{+}}^{*}-\pi_{L}^{*}
$$

that is, the government compensates the enterprise due to the cost of excessive loans. Now we consider the case that the original energy efficiency satisfies $\theta_{0}<1 / 2+\alpha / 2 \rho \kappa$. If the loaning scale received by the enterprise $L$, the thresholds scales $L_{-}, L_{+}$given in (9) and $L^{*}$ given in (10) satisfy the relation 
$L<L_{-}<L^{*}<L_{+}$or $L_{-}<L<L^{*}<L_{+}$, then the government should provide a subsidy for the enterprise before implementing the technical innovation larger than the threshold

$$
S_{b}^{E *}=L^{*}-L
$$

Comparting the difference between the profit with government subsidy before the technical innovation $\pi_{L, S}^{*}$ and the profit of conventional production $\pi_{0}^{*}$, where the profit with a subsidy $\pi_{L, S}^{*}$ is given as

$$
\pi_{L, S}^{*}=\frac{\left(\rho \kappa \theta_{L+S}-\alpha\right)^{2}}{4 \beta}-C_{0}-r L
$$

one can solve the quantity $S$ as

$$
S=\frac{\theta_{0}+\theta_{0} \gamma\left(L-L_{0}\right)-H-H \theta_{0} \gamma\left(L-L_{0}\right)}{H \theta_{0} \gamma-\theta_{0} \gamma}
$$

where

$$
H=\frac{\sqrt{2 \beta r L+\left(\rho \kappa \theta_{0}-\alpha\right)^{2}}+\alpha}{\rho \kappa}
$$

If the relation $L^{*}<L<L_{-}$holds, then the government should provide a subsidy for the enterprise before the technical innovation with a scale larger than $S_{b}^{E *}=S$. Alternatively, the government could provide a subsidy for the enterprise after the technical innovation with a scale larger than $S_{a}^{E *}=\pi_{L_{-}}^{*}-\pi_{L^{*}}^{*}$. In this case, the government determine the threshold of subsidy scale as

$$
S^{E *}=S_{b}^{E *} \wedge S_{a}^{E *}=S \wedge\left(\pi_{L_{-}}^{*}-\pi_{L}^{*}\right)
$$

If the relation $L<L^{*}<L_{-}$holds, then the government could provide a subsidy for the enterprise before the technical innovation with a scale larger than $S_{b}^{E *}=\left(L^{*}-L\right) \vee S$. Alternatively, the government could first provide a subsidy for the enterprise before the technical innovation with scale (larger than) $S_{b}^{E *}=L^{*}-L$ and then provide another subsidy after the technical innovation with a scale larger than $S_{a}^{E *}=\pi_{L_{-}}^{*}-\pi_{L^{*}}^{*}$. Hence, in this case, the government may determine the threshold of subsidy scale as

$$
S^{E *}=\left(\left(L^{*}-L\right) \vee S\right) \wedge\left(L^{*}-L+\pi_{L_{-}}^{*}-\pi_{L^{*}}^{*}\right)
$$

If the relation $L<L_{+}<L^{*}$ holds, then the government could first provide a subsidy for the enterprise before the technical innovation with a scale larger than $S_{b}^{E *}=L^{*}-L$. Then the government provides another subsidy for the enterprise after the technical innovation with a scale larger than $S_{a}^{E *}=\pi_{L_{+}}^{*}-\pi_{L^{*}}^{*}$. Hence, in this case, the government may determine the threshold of subsidy scale as

$$
S^{E *}=L^{*}-L+\pi_{L_{+}}^{*}-\pi_{L^{*}}^{*}
$$

We summarize the discussion in the following proposition.

Proposition 4. If the original energy efficiency of the enterprise is higher than the specific value $1 / 2+\alpha / 2 \rho \kappa$, then we have the following strategy for the decision of the government subsidy. If the practical loaning scale received by the enterprise is lower than the small scale $L_{-}$given in (9), then to stimulate the green innovation, the government should provide a subsidy for the enterprise before the technical innovation larger than the threshold given in (12). If the practical loaning scale received by the enterprise is higher than the large scale $L_{+}$given in (9), the government should provide a subsidy for the enterprise after the technical innovation larger than the threshold given in (13). 
If the original energy efficiency of the enterprise is lower than the specific value $1 / 2+\alpha / 2 \rho \kappa$, then we have the following strategy for the decision of the government subsidy. Firstly, if the threshold scale given in (10) is between the two scales given in (9) meanwhile, the practical loaning scale received by the enterprise is lower than the threshold scale in (10), then to stimulate the green innovation, the government should provide a subsidy for the enterprise larger than the threshold given in (14). Secondly, if the threshold scale in (10) is lower than the small scale $L_{-}$in (9) meanwhile, the practical loaning scale received by the enterprise is between the threshold scale in (10) and the small scale $L_{-}$ in (9), then the government should provide the subsidy for the enterprise larger than the threshold given in (15). Thirdly, if the threshold scale in (10) is lower than the small scale $L_{-}$in (9) meanwhile, the practical loaning scale received by the enterprise is lower than the threshold scale in (10), then the government should provide the subsidy for the enterprise larger than the threshold given in (16). Fourthly, if the threshold scale in (10) is beyond the large scale $L_{+}$in (9) and the practical loaning scale received by the enterprise is lower than large scale $L_{+}$in (9), then the government should provide the subsidy for the enterprise larger than the threshold given in (17).

\section{Conclusions}

In this paper, three participants, the enterprise, the bank, and the government, are involved in the green innovation decision. The enterprise, which is supposed to be a profit seeker, plays a principal role. This is different from most existing literature, where the role of the enterprise is subordinate. In our setting, the energy-intensive enterprise would like to increase the profit through technical innovation, improving energy efficiency. The technical innovation is beneficial to the environment and hence, is green. The financing way is applying for loans from the bank. The bank evaluates the application and makes a decision on the approval of the green loans. To stimulate green innovation development, the government provides necessary subsidies for the enterprise or the bank. We recall the objective of the paper looking for appropriate loaning scales, interest rate and subsidy scales in the green innovation performance. The appropriateness means that the innovation activity should be stimulated and the innovation should be green with these financial resources. By constructing series of models according to game theory and taking analysis, we achieve some useful results as follows.

The stimulation of the technical innovation improving energy efficiency is captured by a two-step strategy. In the first step, the innovation stimulation depends on the lending interest rate. In Proposition 1 , we present a threshold of the lending interest rate. If the lending interest rate exceeds this threshold, then the enterprise will not implement the green innovation project improving its energy efficiency, since the innovation cost is higher than the return after innovating. Thus, the enterprise cannot increase its profit by technical innovation project and the innovation cannot be stimulated. On the other hand, if the lending interest rate is lower than the threshold, then the green innovation stimulation turns into the second step. In the second step, following that the lending interest rate is lower than the given threshold in the first step, the innovation stimulation depends on the green loaning scale. In Proposition 1, we present two thresholds of loaning scale. If the loaning scale for the innovation project lies between these two threshold scales, then the enterprise can increase its profit by technical innovation and thus the green innovation can be stimulated. Otherwise, green innovation fails to be stimulated. If the loaning scale for the innovation project is lower than the small threshold scale, it means that the capital investment is lacking and the profit increase is not remarkable. If the loaning scale for the innovation project exceeds the large threshold scale, it means that excessive capital investment leads to high pressure of debt repayment, which results in the profit decrease. Summarily, as the enterprise is the principal role in the green innovation activity in this paper, hence, from the viewpoint of the enterprise, if, and only if, the lending interest rate is lower than the given threshold and the loaning scale lies between the two threshold scales, the green innovation can be stimulated.

The green effects of technical innovation also depend on the loaning scale. Green innovation and green loans should show their green effects on the environment. The improvement of energy efficiency through technical innovation might lead to more energy input, which results in more energy emission 
into the environment. Thus, the innovation might lose its green effect. In this paper, to prevent this event, we have the following consequence, according to Proposition 2. If the original energy efficiency is larger than some specific value related to unit prices of energy input and final product, and the production efficiency (see Proposition 2), then any loaning scale for the technical innovation larger than the initial acquisition cost will lead to a reduction of emission from the enterprise. Thus, technical innovation shows a green effect. However, if the original energy efficiency is lower than the specific value, then the green effect of innovation depends on the loaning scale. In Proposition 2, we present another threshold of loaning scale. If the loaning scale for the innovation project exceeds this threshold scale, then the emission from the enterprise will be reduced after technical innovation. The technical innovation and the loan show their green effects on the environment. If the loaning scale for technical innovation is lower than the given threshold scale, then the emission from the enterprise increases after technical innovation. Thus, the technical innovation, as well as the loan, cannot show any green effect. Summarily, an energy-intensive enterprise with lower original energy efficiency needs an adequate investment to improve its energy efficiency and realize the green effect of the innovation. On the contrary, an energy-intensive enterprise with higher original energy efficiency only needs a moderate investment to realize the green innovation. Associating with those two thresholds of loaning scale in Proposition 1, these three thresholds of loaning scale should play important roles in green innovation decisions. They provide valuable references for the enterprise and the bank when making decisions on the application for loans to implement technical innovation or evaluating the innovation loans. Some appropriate loaning scales in the green innovation performance can be determined by taking the analysis of the comparison among these three threshold scales (see the analysis behind Proposition 2). We have to emphasize that there exists a special case, that the threshold scale in Proposition 2 might be larger than the large threshold scale in Proposition 1. This leads to a result that there does not exist any appropriate loaning scale in the green innovation decision. To fit this case, government subsidy is introduced and shows its effectiveness.

Government subsidy is an effective approach to stimulate green innovation. The effectiveness is embodied through the subsidy scales. Three forms of government subsidy are considered in the paper, including a subsidy for the bank issuing green loans, subsidy for the enterprise before green innovation, and subsidy for the enterprise after green innovation. In general, green loans are accompanied by low-interest rates. The government compensates for the possible potential loss for the bank due to the issue of green loans with a low-interest rate. In this paper, the subsidy scale for the bank from the government is determined according to Proposition 3. It is the difference between the lending interest with the threshold rate and the practical interest of the enterprise. For the enterprise, the subsidy strategy is a little complicated, since it is dependent on the relations among the three thresholds of loaning scale in Propositions 1 and 2. If the government subsidizes the enterprise before implementing innovation projects, the subsidy will be invested in the innovation project such that the enterprise has more initial capital. Differently, if the government subsidizes the enterprise after implementing innovation project, the subsidy is a pure addition to the profit of the enterprise. The government subsidy strategy is summarized in Proposition 4. We conclude that the subsidy strategy is a branching tree pattern. The first branching depends on the original energy efficiency of the enterprise and the second branching depends on the loaning scale. The government subsidy strategy can provide policymakers with some auxiliary suggestions on the subsidy ways and subsidy scales. According to our government subsidy strategy, the government can provide appropriate loaning scales for the bank and the enterprise through appropriate ways to stimulate green innovation.

In this paper, we focus on appropriate loaning scales and interest rates, as well as appropriate government subsidy scales in green innovation development. Some explicit formulas of loaning scales and interest rates, government subsidy scales are derived, which may provide some valuable references and suggestions for the green innovation stimulation and performance. We achieve these results through constructing game models according to game theory. The enterprise is the principal participant in the game, who is supposed to be completely profit-driven. Hence, the utility function 
is governed by profit. In general, green innovation is accompanied by high risk. The effect of green innovation shows uncertainty. Thus, when making a decision on the green innovation project, the enterprise should consider the innovation risk. The utility function is governed not only by the profit but also by the innovation risk. Both the bank and the government should also care for the risk when stimulating green innovation. We believe that this uncertainty will affect the green loaning scales and interest rate, and the government subsidy scales, which can be embodied by the explicit formulas in our models. The innovation risk will be focused in our forthcoming work. Meanwhile, some empirical results will be involved.

Author Contributions: Methodology, Z.H.; formal analysis, Z.H.; writing-Original draft preparation, S.C.; writing — Review and editing, Z.H.; supervision, B.M.D. and P.F.; funding acquisition, Z.H.

Funding: This research was funded by National Natural Science Foundation of China, grant number 1170115.

Conflicts of Interest: The authors declare no conflict of interest.

\section{References}

1. Zisopoulou, K.; Karalis, S.; Koulouri, M.E.; Pouliasis, G.; Korres, E.; Karousis, A.; Triantafilopoulou, E.; Panagoulia, D. Recasting of the WEF Nexus as an actor with a new economic platform and management model. Energy Policy 2018, 119, 123-139. [CrossRef]

2. Aghion, P.; Hemous, D.; Veugelers, R. No green growth without innovation. Bruegel Policy Brief 2009, 7, 1-8.

3. Abernathy, W.J.; Clark, K.B. Innovation: Mapping the winds of creative destruction. Res. Policy 1985, 14, 3-22. [CrossRef]

4. Diamond, A.M., Jr. Schumpeter's creative destruction: A review of the evidence. J. Priv. Enterp. 2006, 22, 120-146.

5. Driessen, P.H.; Hillebrand, B. Adoption and diffusion of green innovations. In Marketing for Sustainability: Towards Transactional Policy-Making; IOS Press: Amsterdam, The Netherlands, 2002; pp. 343-355.

6. Chen, Y.S.; Lai, S.B.; Wen, C.T. The influence of green innovation performance on corporate advantage in Taiwan. J. Bus. Ethics 2006, 67, 331-339. [CrossRef]

7. Schiederig, T.; Tietze, F.; Herstatt, C. Green innovation in technology and innovation management-An exploratory literature review. RD Manag. 2012, 42, 180-192. [CrossRef]

8. Chang, C.; Chen, Y. Green organizational identity and green innovation. Manag. Decis. 2013, 51, $1056-1070$. [CrossRef]

9. Dutz, M.A.; Sharma, S. Green Growth, Technology and Innovation; The World Bank: Washington, DC, USA, 2012.

10. Janicke, M. “Green growth": From a growing eco-industry to economic sustainability. Energy Policy 2012, 48, 13-21. [CrossRef]

11. Lewis, J.I. Green Innovation in China: China's Wind Power Industry and the Global Transition to a Low-Carbon Economy; Columbia University Press: New York, NY, USA, 2012.

12. Aghion, P.; Bond, S.; Klemm, A.; Marinescu, I. Technology and financial structure: Are innovative firms different? J. Eur. Econ. Assoc. 2004, 2, 277-288. [CrossRef]

13. Bartoloni, E. Capital structure and innovation: Causality and determinants. Empirica 2013, 40, 111-151. [CrossRef]

14. Magri, S. The financing of small innovative firms: The Italian case. Econ. Innov. New Technol. 2009, 18, 181-204. [CrossRef]

15. O'brien, J.P. The capital structure implications of pursuing a strategy of innovation. Strateg. Manag. J. 2003, 24, 415-431. [CrossRef]

16. Schäfer, D.; Werwatz, A.; Zimmermann, V. The determinants of debt and (private) equity financing: The case of young, innovative SMEs from Germany. Ind. Innov. 2004, 11, 225-248. [CrossRef]

17. Del Río, P.; Carrillo-Hermosilla, J.; Könnölä, T.; Bleda, M. Resources, capabilities and competences for eco-innovation. Technol. Econ. Dev. Econ. 2016, 22, 274-292. [CrossRef]

18. Marín-Vinuesa, L.M.; Scarpellini, S.; Portillo-Tarragona, P.; Moneva, J.M. The impact of eco-innovation on performance through the measurement of financial resources and green patents. Organ. Environ. 2018. [CrossRef] 
19. Coad, A.; Pellegrino, G.; Savona, M. Barriers to innovation and firm productivity. Econ. Innov. New Technol. 2016, 25, 321-334. [CrossRef]

20. D'Este, P.; Iammarino, S.; Savona, M.; Von Tunzelmann, N. What hampers innovation? Revealed barriers versus deterring barriers. Res. Policy 2012, 41, 482-488. [CrossRef]

21. Benfratello, L.; Schiantarelli, F.; Sembenelli, A. Banks and innovation: Microeconometric evidence on Italian firms. J. Financ. Econ. 2008, 90, 197-217. [CrossRef]

22. Brown, J.R.; Martinsson, G.; Petersen, B.C. Law, stock markets, and innovation. J. Financ. 2013, 68, 1517-1549. [CrossRef]

23. Kenney, M. How venture capital became a component of the US national system of innovation. Ind. Corp. Chang. 2011, 20, 1677-1723. [CrossRef]

24. Qamruzzaman, M.; Wei, J. Investigation of the asymmetric relationship between financial innovation, banking sector development, and economic growth. Quant. Financ. Econ. 2018, 2, 952-980. [CrossRef]

25. Xin, F.; Zhang, J.; Zheng, W. Does credit market impede innovation? Based on the banking structure analysis. Int. Rev. Econ. Financ. 2017, 52, 268-288. [CrossRef]

26. Hawkins, R.J.; Kuang, H. Lending sociodynamics and drivers of the financial business cycle. Quanttitative Financ. Econ. 2017, 1, 219-252. [CrossRef]

27. Hsu, P.H.; Tian, X.; Xu, Y. Financial development and innovation: Cross-country evidence. J. Financ. Econ. 2014, 112, 116-135. [CrossRef]

28. Amore, M.D.; Schneider, C.; Zaldokas, A. Credit supply and corporate innovation. J. Financ. Econ. 2013, 109, 835-855. [CrossRef]

29. Kim, J.; Park, K. Financial development and deployment of renewable energy technologies. Energy Econ. 2016, 59, 238-250. [CrossRef]

30. Nanda, R.; Nicholas, T. Did bank distress stifle innovation during the Great Depression? J. Financ. Econ. 2014, 114, 273-292. [CrossRef]

31. Zhuang, Z. Financing Investment in Innovation; University of Wisconsin-Madison: Madison, WI, USA, 2013.

32. Li, Z.; Liao, G.; Wang, Z.; Huang, Z. Green loan and subsidy for promoting clean production innovation. J. Clean. Prod. 2018, 187, 421-431. [CrossRef]

33. Huang, Z.; Liao, G.; Li, Z. Loaning scale and government subsidy for promoting green innovation. Technol. Forecast. Soc. Chang. 2019, 144, 148-156. [CrossRef]

34. Calcagnini, G.; Farabullini, F.; Giombini, G. Guarantees and bank loan interest rates in Italian small-sized firms. In Small Businesses in the Aftermath of the Crisis. International Analysis and Policies; Calcagnini, G., Favaretto, I., Eds.; Physica-Verlag: Heidelberg, Germany, 2012; pp. 229-251.

35. Ghisetti, C.; Rennings, K. Environmental innovations and profitability: How does it pay to be green? An empirical analysis on the German innovation survey. J. Clean. Prod. 2014, 75, 106-117. [CrossRef]

36. Zisopoulou, K.; Panagoulia, D. Solar power: A new mathematical definition and theoretical proof it is a green public good. Green Financ. 2019, 1, 312-327. [CrossRef]

37. Paramati, S.R.; Ummalla, M.; Apergis, N. The effect of foreign direct investment and stock market growth on clean energy use across a panel of emerging market economies. Energy Econ. 2016, 56, 29-41. [CrossRef]

38. Berrone, P.; Fosfuri, A.; Gelabert, L.; Gomez-Mejia, L.R. Necessity as the mother of 'green' inventions: Institutional pressures and environmental innovations. Strateg. Manag. J. 2013, 34, 891-909. [CrossRef]

39. Monasterolo, I.; Raberto, M. The EIRIN flow-of-funds behavioural model of green fiscal policies and green sovereign bonds. Ecol. Econ. 2018, 144, 228-243. [CrossRef]

40. Gerlach, H.; Zheng, X. Preferences for green electricity, investment and regulatory incentives. Energy Econ. 2018, 69, 430-441. [CrossRef]

41. Van Leeuwen, G.; Mohnen, P. Revisiting the Porter hypothesis: An empirical analysis of green innovation for the Netherlands. Econ. Innov. New Technol. 2017, 26, 63-77. [CrossRef]

42. Acemoglu, D.; Akcigit, U.; Hanley, D.; Kerr, W. Transition to clean technology. J. Political Econ. 2016, 124, 52-104. [CrossRef]

43. Chen, Z.; Nie, P. Effects of carbon tax on social welfare: A case study of China. Appl. Energy 2016, 183, 1607-1615. [CrossRef]

44. Dzonzi-Undi, J.; Li, S. Policy influence on clean coal uptake in China, India, Australia, and USA. Environ. Prog. Sustain. Energy 2016, 35, 906-913. [CrossRef] 
45. Wang, C.; Nie, P.; Peng, D.; Li, Z. Green insurance subsidy for promoting clean production innovation. J. Clean. Prod. 2017, 148, 111-117. [CrossRef]

46. Kemfert, C.; Schmalz, S. Sustainable finance: Political challenges of development and implementation of framework conditions. Green Financ. 2019, 1, 237-248. [CrossRef]

47. Tsai, K.H.; Liao, Y.C. Sustainability strategy and eco-innovation: A moderation model. Bus. Strategy Environ. 2017, 26, 426-437. [CrossRef]

48. Huang, Y.; Wang, K.; Zhang, T.; Pang, C. Green supply chain coordination with greenhouse gases emissions management: A game-theoretic approach. J. Clean. Prod. 2016, 112, 2004-2014. [CrossRef]

49. Tian, Y.; Govindan, K.; Zhu, Q. A system dynamics model based on evolutionary game theory for green supply chain management diffusion among Chinese manufactures. J. Clean. Prod. 2014, 80, 96-105. [CrossRef]

50. Hafezalkotob, A.; Alavi, A.; Makui, A. Government financial intervention in green and regular supply chains: Multi-level game theory approach. Int. J. Manag. Sci. Eng. Manag. 2016, 11, 167-177. [CrossRef]

51. Dafermos, Y.; Nikolaidi, M.; Galanis, G. Climate change, financial stability and monetary policy. Ecol. Econ. 2018, 152, 219-234. [CrossRef]

52. Accenture. Innovation Maturity Index 2018 (Middle East); Accenture: Dublin, Ireland, 2018.

53. Force, G.F.T. Establishing China's Green Financial System; People's Bank of China \& United Nations Environment Programme: Beijing, China, 2015.

54. NGFS. A Call for Action: Climate Change as a Source of Financial Risk; Network for Greening the Financial System: Paris, France, 2019.

(C) 2019 by the authors. Licensee MDPI, Basel, Switzerland. This article is an open access article distributed under the terms and conditions of the Creative Commons Attribution (CC BY) license (http://creativecommons.org/licenses/by/4.0/). 